\title{
Sustentabilidade Empresarial no agronegócio: Percursos e implicações nas práticas
}

\section{brasileiras}

\author{
Corporate Sustainability in agribusiness: Paths and implications for Brazilian practices \\ Sostenibilidad Empresarial em la agroindústria: Caminos e implicaciones para las prácticas \\ brasileñas
}

Recebido: 27/05/2021 | Revisado: 04/06/2021 | Aceito: 07/06/2021 | Publicado: 22/06/2021

\author{
Najara Escarião Agripino \\ ORCID: https://orcid.org/0000-0001-8659-8258 \\ Universidade Federal de Campina Grande, Brasil \\ E-mail: najaraagripino@gmail.com \\ Kettrin Farias Bem Maracajá \\ ORCID: https://orcid.org/0000-0002-8189-109X \\ Universidade Federal de Campina Grande, Brasil \\ E-mail: kettrin.farias@ufcg.edu.br \\ Petruska Araújo Machado \\ ORCID: https://orcid.org/0000-0003-1107-8180 \\ Universidade Federal de Campina Grande, Brasil \\ E-mail: petruskamachado@gmail.com
}

\begin{abstract}
Resumo
A agropecuária brasileira é referência mundial em diversificação, produtividade, emprego e desenvolvimento de tecnologias e práticas sustentáveis. Contudo, sua imagem também está associada a impactos ambientais e sociais negativos o que tem acarretado em barreiras a comercialização dos produtos. Nos últimos dois anos, em virtude da nova política ambiental adotada pelo governo que tem por intuito abrandar a legislação ambiental vigente, o agronegócio brasileiro tem se tornado tema central das discussões em nível global sobre os impactos gerados pelo mercado agropecuário. Com base nisso, o estudo pretende por meio de uma pesquisa bibliográfica e documental compreender o processo histórico da sustentabilidade empresarial e as implicações da sua incorporação no contexto do agronegócio brasileiro. Embora as projeções para o setor sejam de expansão e crescimento econômico, entende-se como imprescindível aos produtores nacionais atuar em consonância com a conscientização do mercado consumidor frente a preservação ambiental e apesar da nova política ambiental de abrandar a legislação, busquem aliar a produção à Sustentabilidade Empresarial.
\end{abstract}

Palavras-chave: Práticas de sustentabilidade; Agropecuária brasileira; Sustentabilidade empresarial.

\begin{abstract}
Brazilian agriculture is a world reference in diversification, productivity, employment and development of sustainable technologies and practices. However, its image is also associated with negative environmental and social impacts, which has caused barriers to the sale of products. In the last two years, due to the new environmental policy adopted by the government that aims to soften the current environmental legislation, Brazilian agribusiness has become a central theme of discussions at the global level on the impacts generated by the agricultural market. Based on this, the study intends, by means of a literature review, to understand the historical process of corporate sustainability and the implications of its incorporation in the context of Brazilian agribusiness. Although the projections for the sector are of expansion and economic growth, it is understood as essential for national producers to act in line with the awareness of the consumer market regarding environmental preservation and despite the new environmental policy of easing the legislation, seek to combine production with Corporate sustainability.
\end{abstract}

Keywords: Sustainability practices; Brazilian agriculture; Corporate sustainability.

\section{Resumen}

La agricultura brasileña es una referencia mundial en diversificación, productividad, empleo y desarrollo de tecnologías y prácticas sostenibles. Sin embargo, su imagen también está asociada a impactos ambientales y sociales negativos, lo que ha generado barreras a la venta de productos. En los últimos dos años, debido a la nueva política ambiental adoptada por el gobierno que apunta a suavizar la actual legislación ambiental, la agroindustria brasileña se ha convertido en un tema central de discusión a nivel global sobre los impactos generados por el mercado agrícola. Con base en esto, el estudio pretende, mediante una revisión de la literatura, comprender el proceso histórico de la sustentabilidad empresarial y las implicaciones de su incorporación en el contexto de la 
agroindustria brasileña. Si bien las proyecciones para el sector son de expansión y crecimiento económico, se entiende como fundamental que los productores nacionales actúen en línea con la conciencia del mercado consumidor respecto a la preservación ambiental y a pesar de la nueva política ambiental de flexibilización de la legislación, busquen combinar la producción. con sostenibilidad empresarial.

Palabras clave: Prácticas de sostenibilidad; Agricultura brasileña; Sostenibilidad corporativa.

\section{Introdução}

O Brasil é um país tradicionalmente agrícola. Sua história com a agropecuária teve início antes mesmo da chegada dos colonizadores. De acordo com Calmon (2002), os povos primitivos já praticavam a agricultura e o extrativismo de subsistência. Os produtos cultivados pelos nativos eram feijão, milho, batata doce e mandioca da qual fabricavam a farinha, sendo esta, seu principal alimento. O cultivo desses alimentos era realizado apenas para o consumo da aldeia, havendo poucas trocas desses gêneros com aldeias vizinhas. Após o descobrimento, o agronegócio tem sido um forte segmento da economia do Brasil, com diferentes ciclos econômicos, entre eles os ciclos do pau brasil (1500-1530), açúcar (1530-1690), café (18001930), borracha (1879-1912, revigorando-se por pouco tempo entre 1942-1945), cacau (1890-1931), algodão (meados de 1917-1977), soja e carnes (anos 2000 aos dias atuais) (Calmon, 1937; 2002; Albuquerque, 1977).

No âmbito econômico, o agronegócio tem alcançado excelentes resultados, atingindo vários recordes na produção de grãos. Além disso, no ano de 2020 o Brasil se consolidou como o maior exportador de carne bovina do mundo, com 2,2 milhões de toneladas exportadas, cerca de 14,4\% do total mundial (Ministério da Agricultura, Pecuária e Abastecimento, [MAPA], 2020). Mas apesar do seu desempenho (Ministério da Agricultura, Pecuária e Abastecimento, 2020), a imagem do agronegócio brasileiro também está associada ao acirramento de problemas sociais e ambientais. Como por exemplo, a exploração de mão de obra, desmatamento, emissão de gases poluentes em virtude das queimadas e fertilização química dos solos (Bruno, 2019; Romano \& Vega, 2019; Menezes, 2019).

Soma-se a isso, a redução da fiscalização ambiental por parte do governo brasileiro, com diminuição de cerca de 9,97\% de funcionários nos principais órgãos fiscalizadores, Ministério do Meio Ambiente (MMA), Instituto Brasileiro do Meio Ambiente e dos Recursos Naturais Renováveis (IBAMA) e Instituto Chico Mendes de Conservação da Biodiversidade (ICMBio), totalizando 578 servidores a menos a partir do ano de 2019 (Shalders, 2021; Governo do Brasil, 2021). Tal diminuição contribui ainda mais para dificultar a aplicação das políticas ambientais. Como resultado, teve-se o aumento do desmatamento e ocorrência de incêndios em biomas como os da Amazônia e Pantanal entre os anos de 2019 e 2020 (Greenpeace Brasil, 2020). Contudo, a conscientização dos diferentes agentes sociais sobre os impactos socioambientais e as constantes ameaças externas de impor barreiras comerciais não tarifárias aos produtos brasileiros, têm contribuído gradualmente para as discussões sobre mudanças a serem adotadas para transformação deste quadro.

Estudos realizados no Brasil e que abordam as práticas de sustentabilidade em unidades agropecuárias após as mudanças ocorridas na política ambiental ainda são poucos. Neste escopo, destacamos o estudo de Santos, Walter e Bertolini (2019) que abordam a adoção de práticas de sustentabilidade como estratégia de legitimidade organizacional; Smalci, Silva, Fernandes e Quel (2020) que pesquisaram sobre os desafios enfrentados pelo agronegócio brasileiro para aumento da produtividade e competitividade e a inovação como criação de valor dos produtos das empresas do setor; Tarapanoff (2017), traz uma análise sobre o contexto atual do agronegócio brasileiro focalizando as informações a serem observadas frente aos desafios da globalização e dos mandatos da sustentabilidade. O estudo também destaca os ganhos nas práticas de sustentabilidade já adotadas pelo agronegócio; Melo, Brandão e Lima (2018) analisam as características atuais do capitalismo no campo e nas práticas agropecuárias com a instauração de uma nova racionalidade técnica no âmbito das relações sociais e ambientais inseridas no meio técnico-científico-informacional. 
Apontamos ainda o trabalho de Costa e Lino (2018), que realiza uma análise do desenvolvimento do agronegócio frente ao prisma social e ambiental, considerando o fator humano e as políticas públicas ambientais direcionadas ao setor. $\mathrm{O}$ estudo cita a agenda ambiental adotada no ano de 2017 que propõe a flexibilização nas regras de licenciamento ambiental, liberação de agrotóxicos, venda de terras para estrangeiros, e proposição de uma medida provisória com intuito de anistiar multas; Pletsch, Casali, Baggio e Turcato (2019) propuseram avaliar a Sustentabilidade Ambiental das propriedades rurais do município de Três Passos-RS praticantes da suinocultura e bovinocultura; Guimarães e Pireneus (2020) trazem uma descrição do panorama jurídico-político da agroecologia nacional; Rossi e Santos (2018) trazem uma análise da dimensão política dos conflitos socioambientais que envolvem as águas no Brasil e como se configuram na bacia do Rio Salitre-BA.; Lima Filho, Azevedo, Teixeira e Silva (2017), abordam os diálogos entre os stakeholders do setor de bovinocultura de corte matogrossense frente a sustentabilidade e mudanças climáticas; e Barbarini e Mário (2019) discutem a correlação entre as novas práticas e a problemática da alimentação, considerando as principais políticas públicas nesse campo, e as teorias da justiça social.

Embora indiscutivelmente os estudos tragam relevantes contribuições para a compreensão sobre o cenário atual do agronegócio brasileiro, identificou-se como lacuna de pesquisa a imersão nas implicações da adoção de práticas sustentáveis no setor agropecuário frente ao novo cenário da política ambiental brasileira e as implicações nas transações internacionais. Devido a vinculação do setor à ocupação e exploração das terras produtivas, influência no crescimento econômico, bem como, importância na balança comercial, geração de emprego e renda e impactos ambientais, o estudo do tema torna-se relevante, especialmente devido as novas tendências sustentáveis do mercado internacional.

Considerando o contexto, o estudo levanta como problemática de pesquisa compreender: Quais as implicações da incorporação da Sustentabilidade Empresarial no agronegócio brasileiro? A partir do problema levantado, propõe-se compreender o processo histórico da sustentabilidade empresarial e as implicações da sua incorporação no contexto do agronegócio no Brasil.

Para melhor entendimento do cenário em que se encontra o setor agropecuário nacional e as ações voltadas ao alcance da sustentabilidade no segmento, estruturou-se a pesquisa em cinco tópicos: aporte teórico sobre a sustentabilidade empresarial, o qual apresenta o contexto histórico e os conceitos relacionados ao tema; a sustentabilidade no agronegócio brasileiro, no qual se apresenta o panorama do setor e as previsões para o futuro; procedimentos metodológicos, o qual apresenta os métodos aplicados no desenvolvimento da pesquisa; apresentação e discussão dos resultados, no qual são discutidas as implicações da sustentabilidade empresarial no agronegócio. E por fim, a conclusão, com uma síntese das discussões realizadas no texto.

\section{Metodologia}

Conforme Vergara (2007), este estudo está classificado em pesquisa descritiva quanto aos seus fins e documental e bibliográfica quanto aos seus meios. Quanto a forma de abordagem, é uma pesquisa puramente qualitativa. Justifica-se a escolha dos métodos supracitados, em função do objetivo de obter maior aprofundamento na descrição do tema abordado (Trivinõs, 2008) e em função das fontes utilizadas para obtenção dos dados. Os dados foram coletados através do levantamento das produções científicas na base de dados Web of Science e Portal Capes e em livros, teses e dissertações. Já para a pesquisa documental, recorreu-se aos documentos oficiais e matérias em sites jornalísticos e institucionais.

A busca bibliográfica foi realizada em dois momentos. Em um primeiro momento, recorreu-se a base de dados Web of Science, utilizando-se como descritores as palavras "Corporate Sustainability" e "Sustainability in Agribusiness" com a combinação boleana "or". A pesquisa foi realizada no dia 25 de maio de 2021 e foram apontados 1.766 documentos. A partir da base delimitou-se os documentos para apenas artigos científicos publicados nos idiomas inglês e português nos Estados 
Unidos e Brasil entre os anos de 2005 e 2021. O período foi definido com vistas a coletar informações sobre os últimos quinze anos dos estudos sobre o tema. Os países e idiomas foram delimitados considerando o país que mais publicou sobre o tema (EUA) e devido ao objetivo inicial do estudo, abordar o agronegócio brasileiro (Brasil). Também foram definidas as áreas relacionadas a pesquisa "Management", "Business", "Business Finance", "Economics”, resultando em 209 artigos.

Para a organização das informações, contidas nas publicações científicas encontradas, foi utilizada a leitura preliminar dos títulos e resumos dos trabalhos, identificando-se o objeto, objetivos do estudo e a pesquisa. Posteriormente, também foi realizada uma pesquisa na base de dados do Portal Capes, no dia 26 de maio de 2021 utilizando as palavras-chaves "Sustentabilidade Empresarial", "Sustentabilidade no Agronegócio" e "Práticas Sustentáveis no Agronegócio". Nesta segunda etapa da pesquisa, foram apresentados 36 documentos. A seleção do material seguiu os mesmos critérios da pesquisa inicial, leitura preliminar dos títulos e resumos dos trabalhos, identificando-se o objeto, objetivos do estudo e a pesquisa. Por fim, foram utilizados livros, dissertações e teses em versões impressas ou pdf disponíveis em bibliotecas de universidades públicas para complementar o referencial teórico do estudo. Na Figura 1, destaca-se o processo de seleção dos artigos.

Figura 1: Filtragem e seleção dos artigos utilizados.

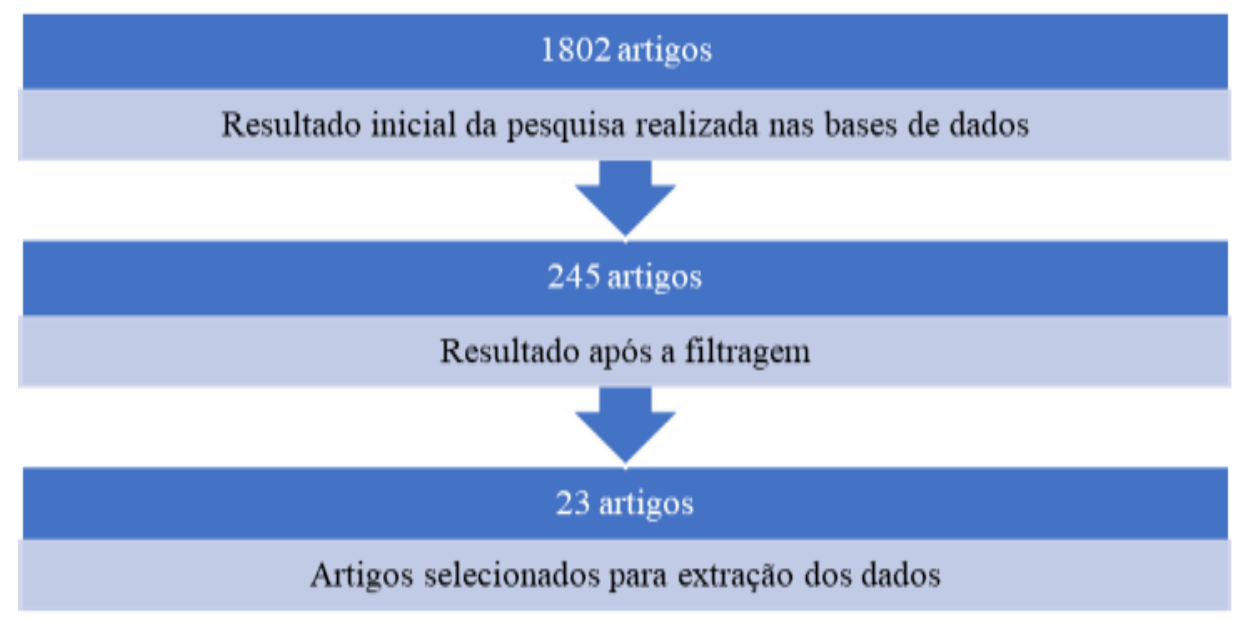

Fonte: Autoras.

Após a realização da pesquisa nos bancos de dados, o processo de exclusão dos artigos seguiu o critério da relevância ao tema. Selecionados os artigos, procedeu-se a análise de conteúdo em três etapas: pré-análise, descrição analítica e interpretação inferencial, seguindo as orientações de Bardin (2016). Os resultados encontrados foram discutidos nos tópicos adiante.

\section{Aporte Teórico sobre a Sustentabilidade Empresarial}

As reflexões sobre o papel das empresas na manutenção da vida do planeta e sua responsabilidade frente aos impactos sociais e ambientais foram fortemente influenciadas pelos movimentos reivindicatórios ocorridos entre os séculos XIX e XX. Conforme Reis e Medeiros (2009), o julgamento do caso Dodge versus Ford, ocorrido nos Estados Unidos em 1919, que tratava da competência do presidente e acionista Henry Ford em tomar decisões de caráter social que contrariavam os interesses dos também acionistas John e Horace Dodge, iria instigar a dialógica sobre a Responsabilidade Social Corporativa (RSC) das empresas e a visão social sobre a ética e a livre escolha dos dirigentes.

O final favorável do processo para os acionistas Dodge estava de acordo com os regulamentos legais da época, o qual se baseava no pensamento econômico da escola clássica que não previa compromisso das empresas com as questões sociais. 
Nesse período, uma empresa socialmente responsável era aquela comprometida com as expectativas de seus próprios acionistas e a maximização dos seus lucros. Assim, as empresas que atendessem a esses interesses estariam ao mesmo tempo, gerando empregos, pagando impostos e ofertando produtos e serviços, enquanto os custos sociais estariam a cargo dos governos (Carmo, 2015).

Para Ashley (2005), o marco que suscitou o crescimento do debate acerca da RSC foi o quadro provocado pela quebra da Bolsa de Nova York em 1929. A crise econômica que se seguiu após o episódio levantou questionamentos sobre as promessas do liberalismo econômico e reacendeu a controvérsia sobre a RSC das empresas no contexto social em que estão inseridas.

O segundo episódio a fortalecer as discussões acerca da RSC, foi também um caso de ação judicial, ocorrido em 1953 e que ficou conhecido como o caso A. P. Smith Manufacturing Company verus Barlow. O julgamento dizia respeito a doações de recursos corporativos à Universidade de Princeton, em contraposição ao posicionamento do grupo de acionistas. Neste caso, a Suprema Corte de Nova Jersey deu parecer favorável à doação, aduzindo seus benefícios ao país e que tal postura era consoante com o novo contexto em que as ações empresariais filantrópicas deveriam ser estimuladas (Maia, 2015).

A partir desse episódio, as reflexões sobre os interesses corporativos restritos aos lucros dos seus acionistas tomariam outros contornos frente as novas interpretações das cortes superiores favoráveis a filantropia corporativa, bem como, da própria mudança de percepção dos agentes e acionistas sobre o valor estratégico das ações sociais para os objetivos do negócio (Carmo, 2015).

A década de 1970 foi o período em que surgiram os estudos relativos a RSC, tais estudos, estavam divididos em duas correntes antagônicas distintas: uma que defendia a primazia dos interesses dos acionistas como finalidade das organizações e outra que apregoavam que as empresas deveriam identificar e incorporar as expectativas e necessidades de todos os stakeholders da organização. Ambas as correntes foram fundamentais para moldar a perspectiva e as práticas relacionadas à RSC visto que a visão centrada unicamente na função econômica já não seria suficiente para orientar a gestão dos negócios diante dos novos valores compartilhados pela sociedade pós-industrial, como a valorização da vida humana e respeito ao meio ambiente (Ashley, 2005).

Em paralelo a essas discussões, a questão ambiental também ganhava relevância no campo dos debates organizacionais. Carroll e Shabana (2010) ponderam que a partir do início deste milênio, a sustentabilidade e o desenvolvimento sustentável adquiriram tal relevância entre a comunidade empresarial, que o tema passou a dividir espaço na academia com as arguições teóricas relativas a RSC.

Barbieri e Cajazeiras (2012) destacam que os eventos mundiais sobre as questões ambientais como a Conferência de Estocolmo (1972), foram fundamentais para a aproximação da temática ambiental com a RSC, razão pela qual as atuais abordagens sobre RSC presentes na literatura tratam a questão ambiental como um dos temas a serem considerados na gestão dos negócios.

A partir da junção das dimensões social e ambiental no processo de gestão das organizações, surge uma nova compreensão sobre o papel das empresas, atualmente vistas como um sistema social organizado, no qual se desenvolvem relações diversas, além daquelas estritamente econômicas. No contexto empresarial, o conceito da sustentabilidade está relacionado à manutenção das atividades de forma produtiva e rentável, integrada a equidade social e preservação ambiental de forma harmônica e complementar para o alcance dos objetivos organizacionais (Oliveira, 2012).

De acordo com Almeida (2002), a dimensão ecológica ou ambiental motiva as empresas a considerarem o impacto de suas atividades e contribui para a inserção da administração ambiental na rotina da organização. Já a dimensão social converge no aspecto social integrado às qualidades humanas, como suas habilidades, dedicação e experiências, abrangendo tanto o ambiente interno quanto externo das organizações. 
Para Donaire (1999), com a crescente demanda e preocupação da sociedade atual para com o meio ambiente, segurança, defesa do consumidor, etc., é imperativo as empresas a adoção da responsabilidade socioambiental, o que acaba por proporcionar melhoria da imagem, que resulta em mais consumidores, aumento no volume das vendas, melhores empregados e fornecedores, facilidade de acesso ao mercado de capitais, entre outras. O que ao longo prazo representa a maximização dos seus lucros e melhor posicionamento da marca.

Assim, a difusão da sustentabilidade na esfera organizacional, dar-se por meio da gestão organizacional, sendo a alta administração a responsável por perceber e transformar a sensibilização da organização no que confere aos problemas socioambientais, seja no ambiente interno ou externo. É a partir do comprometimento da alta administração que os esforços em busca da melhoria da qualidade ambiental dos processos e produtos podem ser alcançados (Claro, Claro \& Amâncio, 2008).

Foi devido a demanda estratégica pela consideração das dimensões econômica, ambiental e social no planejamento da rotina de trabalho das empresas, que em 1977, Jonh Elkington, propôs a incorporação do tripé da sustentabilidade à gestão das organizações, o que ficou conhecido por Triple Bottom Line, também chamado de Tripé da Sustentabilidade Empresarial, um novo modelo que contempla em suas decisões estratégicas, o bottomline econômico, o bottomline social e o bottomline ambiental (Vellani \& Ribeiro, 2009).

Elkington (1997) sugeriu às empresas que avaliassem seus resultados não somente pelo viés do desempenho financeiro, geralmente expresso nos retornos sobre investimentos e lucratividade, mas também, pelo viés do seu impacto sobre a economia, meio ambiente e sociedade. Inicialmente, o tripé do conceito de desenvolvimento sustentável foi publicado no relatório de Brundtland, porém não de forma integrada. A integração entre os três pilares nas práticas da sustentabilidade foi uma proposta de Elkington para o contexto corporativo (Barbieri \& Cajazeira, 2012).

Destarte, o tripé da sustentabilidade é aplicado nas empresas como uma ferramenta que auxilia na mensuração do desempenho organizacional e os compara com os fatores econômicos, ambientais e sociais. De um modo geral, o Triple BottomLine é aplicado para estabelecer valores e processos que as organizações devem adotar a fim de reduzir os impactos causados nas esferas social, ambiental e econômica (Spers, Mota \& Martineli, 2014).

Parmar, Freeman, Harrison, Wicks e Purnell (2020) ponderam que a sustentabilidade empresarial se baseia nos conceitos de desenvolvimento sustentável, RSC e Teoria dos Stakeholders. Dessa forma, a Sustentabilidade Empresarial consiste em um sistema de gestão baseado no controle ambiental sobre o processo produtivo, serviços e planejamento de programas para educação ambiental, no intuito de externar junto a sociedade sua preocupação com o meio ambiente e demandas sociais (Székely \& Knirsch, 2005).

Strobel (2005) discorre que a sustentabilidade deve ser observada pela esfera econômica, na qual as empresas devem ser economicamente viáveis, visto seu papel social de dar retorno financeiro aos investimentos realizados pelo capital privado; pelo ponto de vista social, no qual a empresa deve satisfazer às premissas de proporcionar a melhoria das condições de trabalho dos seus colaboradores, respeitando a diversidade cultural presente na sociedade em que atua, além de promover oportunidades às pessoas portadoras de necessidades especiais.

A sustentabilidade social prevê o processo de desenvolvimento que proporcione um crescimento estável com distribuição igualitária de renda, de modo a buscar a melhoria das condições de vida das populações; na perspectiva ambiental, a organização deve estar alicerçada na ecoeficiência dos seus processos produtivos, bem como, adotar a produção mais limpa, favorecer o desenvolvimento de uma cultura ambiental organizacional, adotar uma postura ambientalmente responsável, e preocupar-se dos impactos gerados pelas atividades humanas sobre o meio ambiente (Strobel, 2005).

Assim, a sustentabilidade só poderá ser atingida caso a organização atenda aos critérios do economicamente viável, socialmente justo e ambientalmente correto, promovendo o desenvolvimento social da comunidade em que atua, respeitando sua biodiversidade e beneficiando a sociedade como um todo. 
Vale lembrar, que dentro dos conceitos da sustentabilidade, as dimensões social e ambiental não podem ser dissociadas. Dessa forma, compreender uma organização como ecologicamente sustentável, é também, percebê-la como socialmente responsável. Assim, as organizações sustentáveis devem voltar sua operacionalização a estratégias ambientais complexas, atuando em redes e executando projetos cooperativos visando a equidade social e conservação da vida planetária.

Algumas organizações, como as atuantes no setor agropecuário demandam uma maior complexidade na gestão sustentável de seus negócios, o que se deve em razão das suas práticas impactarem diretamente no ambiente natural e na comunidade no entorno, o que será abordado adiante.

\section{A Sustentabilidade no Agronegócio Brasileiro}

Apesar do cenário difícil para a economia no ano de 2020, o setor agropecuário brasileiro foi o único a apresentar crescimento durante a pandemia do COVID-19, resultado alcançado especialmente pelo bom desempenho do comércio da soja no primeiro trimestre do ano, com taxa de 0,6\% em comparação ao quarto trimestre de 2019 (Instituto Brasileiro de Geografia e Estatística [IBGE], 2020).

No que se refere às exportações, foi registrado valor recorde em abril, ultrapassando pela primeira vez a marca de US\$ 10 bilhões em um mês. Já o Produto Interno Bruto (PIB) obteve alta de 2,5\% (IBGE, 2020). Com base nesses resultados, espera-se que em 2021 o PIB da agropecuária tenha um aumento de 1,2\% e os setores mais beneficiados sejam os produtores de soja, a indústria sulcroalcooleira e os segmentos bovinos e suínos (Instituto de Pesquisa Econômica Aplicada [IPEA], 2020).

A grande importância econômica da agropecuária para o Brasil se deve em grande parte pelo dinamismo do setor que atende tanto a demanda doméstica por alimentos e matérias-primas, quanto às indústrias, tornando-se um dos grandes responsáveis pelo equilíbrio entre as contas externas do país. Além disso, atuam no segmento desde pequenos produtores individuais à grandes firmas com produção de larga escala. Sua atuação depende da região e das commodities mais propícias a serem produzidas em cada uma delas, o que também contribui para o desenvolvimento regional onde cada uma delas é produzida. Quanto à demanda pela produção, o setor atende intermediários e o consumidor final. Entre os intermediários estão atacadistas, processadoras agroindustriais, etc., sendo os principais mercados de processadoras, os Estados Unidos, Japão e União Europeia. A preferência desses países pela industrialização de matérias-primas e a estrutura tributária, que facilitam a exportação do produto primário, reforçam a posição do Brasil como um dos maiores exportadores de produtos primários (Amaral \& Guimarães, 2020).

Como principal fator de competitividade das empresas agropecuárias brasileiras, tem-se o custo da produção mais competitivo que os dos concorrentes estrangeiros, o que se dá em virtude do clima favorável, ampla extensão de terras cultiváveis disponíveis e a existência de instituições de pesquisa que fomentam a agropecuária, como a Empresa Brasileira de Pesquisa Agropecuária [EMBRAPA]. Quanto aos pontos fracos do setor, é possível apontar a infraestrutura logística, que dificulta o escoamento e aumento da produção, ausência de armazéns para estocagem das crescentes safras e alto custo dos fretes que inviabilizam economicamente a produção em determinadas regiões do país (Amaral \& Guimarães, 2020).

No que diz respeito aos aspectos ambientais, as áreas rurais são significativas no que tange a prestação de serviços ao ambiente natural, como: proteção da biodiversidade, conservação e oferta de água, manutenção das condições climáticas, etc. (Souza, 2012). Quanto aos aspectos sociais, o desenvolvimento das áreas rurais tem promovido a emancipação da população campesina, desenvolvimento de novas habilidades dos trabalhadores para inserção em novos mercados e melhoria das condições de vida dos agricultores e comunidades no entorno (Schneider, 2010).

Em contrapartida, os negócios rurais são apontados como grandes responsáveis pelos impactos ambientais provocados no país, tais como o desmatamento, queimadas, uso e ocupação inadequada do solo, práticas agrícolas incorretas, 
contaminação das águas e solo com fertilizantes, extinção de espécies e habitats, entre outros (Souza, 2012; Gomes, 2019). Referente aos aspectos sociais e econômicos, o ponto negro do agronegócio centra-se na luta latifundiária, condições precárias de trabalho, grilagem de terras, concentração de riqueza entre os grandes produtores - o Brasil é o quinto lugar no ranking de desigualdade ao acesso à terra. Estima-se que $45 \%$ da área produtiva concentra-se em propriedades superiores a mil hectares -, forte presença de multinacionais que exploram as terras para produção de commodities, e especulação financeira (Santos \& Glass, 2018).

Diante dos problemas associados à agropecuária, faz-se imprescindível e estratégico a inserção das propriedades rurais no debate sobre a sustentabilidade ambiental. De acordo com Almeida (2002), uma empresa para ser sustentável deve buscar em todas as suas ações e decisões a ecoeficiência, procurando produzir mais e com melhor qualidade gerando menos poluição e utilizando menos recursos naturais. A empresa que é partidária dos princípios da sustentabilidade deve ainda ser socialmente responsável, assumindo que está imersa num ambiente social em que influi ao mesmo tempo em que sofre influência. A motivação dos líderes empresariais deve ser respaldada numa visão de longo prazo, em que se leve em consideração os custos futuros e não somente os custos presentes.

A incorporação da sustentabilidade no universo empresarial vai estar condicionada a vários aspectos como as crenças do próprio dirigente da empresa, a mobilização da sociedade, a influência do mercado nacional e internacional, a atuação do setor público, a pressão de organismos internacionais, entre inúmeros outros fatores de ordem conjuntural (Barros, Andrade, Vasconcelos \& Cândido, 2010). Com base nisso, é mister que as empresas atuantes neste setor estejam cientes das implicações da adoção de práticas sustentáveis, o que será debatido no tópico adiante.

\section{Apresentação dos Resultados}

Ante as discussões sobre a sustentabilidade, o setor agropecuário brasileiro ocupa lugar de destaque, o que se justifica não somente pela sua importância para a economia do país, extensão da área ocupada para o desenvolvimento dos sistemas agroindustriais e a relevância estratégica dos produtos resultantes dessa atividade - geralmente alimentos ou derivados que são responsáveis pela segurança alimentar da população, sendo o terceiro maior produtor de alimentos do mundo -, mas também, por estar no centro dos debates sobre responsabilidade socioambiental.

Além da produção de alimentos indispensável para o abastecimento do mercado nacional, as propriedades rurais contribuem economicamente com o país, na geração de emprego e renda a inúmeras famílias, especialmente as pertencentes às comunidades em que os empreendimentos rurais se encontram inseridos; o setor representa 21,4\% do PIB brasileiro total; sustenta com insumos e matérias-primas outros setores da economia - como o têxtil, farmacêutico e biocombustíveis -; representou em 2019, 43\% do total das exportações do país, o que nos coloca no quarto lugar no ranking mundial em exportação de produtos agropecuários, atrás apenas da União Europeia, EUA e China, garantindo sucessivos superávits cambiais positivas à Balança Comercial Brasileira (Centro de Estudos Avançados em Economia Aplicada [CEPEA], 2020; IBGE, 2017).

Assim, a demanda crescente por terras cultiváveis e para pasto no Brasil e no mundo desperta para a necessidade da adoção de mecanismos que possam promover a sustentabilidade nas práticas agrícolas e pecuárias de modo a atender aos altos níveis de produção sem comprometer o equilíbrio ecológico (Soglio, 2016).

Conforme Reijntnes, Haverkort e Waters-Bayer (1992), compreende-se a agricultura sustentável como meio da prática da atividade agrícola que promova o equilíbrio ecológico, viabilidade econômica e equidade social. Para a Organização das Nações Unidas para Agricultura e Alimentação (1999), a agricultura sustentável envolve a conservação do solo, água e recursos genéticos animais e vegetais, bem como, a conservação ambiental e emprego de técnicas apropriadas e viáveis econômica e socialmente. 
A esse respeito, Brasil e Paraguai são os dois países do mundo a estabelecer cotas de preservação de vegetação nativa à conta do agricultor, enquanto em outros países, os custos de proteção ambiental - quando existem - são rateados entre os cidadãos, por meio de parques e reservas florestais e custeados pelo poder público. Assim, apenas $31 \%$ da área total do território brasileiro é dedicado à agropecuária, uma das razões pelas quais mais de $60 \%$ da cobertura vegetal original ainda está preservada (Gazzoni, 2013).

Outas práticas de conservação ambiental adotadas na produção brasileira são o plantio direto, considerado uma prática conservacionista de produção (Silva, Galon, Ferreira, Tiron, Ferreira, Silva, Aspiazú \& Agnes, 2009); redução do consumo de diesel e de água, a partir do desenvolvimento de tecnologias sustentáveis; desenvolvimento e adoção de novas tecnologias voltadas ao setor, o que possibilita aumento da produtividade, qualidade da produção e desenvolvimento de sementes para uma plantação mais adaptada a diversas condições ambientais (Kirschner, Vione, Fernandes \& Thesing, 2020).

Cavalcanti Filho e Cartaxo (2015) elencam ainda como principais áreas de atuação para uma agropecuária sustentável a agroenergia, manejo sustentável da água, uso eficiente da terra, biodiversidade e produção para o consumo consciente. Com relação ao comércio exterior, as práticas de produção sustentáveis vêm sendo exigidas pelos mercados internacionais e tem se tornado uma tendência imposta pelas pressões globais diante da necessidade de preservação do meio ambiente e que devem ser atendidas por governos e empresários (Melo, Silva \& Queiroz, 2014).

O contexto atual do agronegócio brasileiro ilustra bem como o mercado e os organismos internacionais exercem pressão sobre as políticas ambientais de um país ou mesmo sobre um setor da economia. Apesar dos grandes avanços em termos de desenvolvimento sustentável e imposição de uma legislação voltada a preservação ambiental, nos últimos anos, os produtos oriundos da agropecuária brasileira vêm sendo fortemente associados às queimadas e desmatamentos na Amazônia. Entre os anos de 2019 e 2020 os produtos brasileiros tem adquirido uma reputação negativa no exterior, como resultado, medidas tomadas pelo Reino Unido e Alemanha para boicotar as exportações brasileiras tem influenciado discussões em diversos outros países importadores (Jornal do Brasil, 2020).

Além disso, cerca de sete empresas ${ }^{1}$ de gerenciamento de ativos ameaçaram parar de investir em empresas nacionais produtoras de carne, grãos e até em títulos do governo. As medidas têm por objetivo pressionar o governo brasileiro a rever medidas que flexibilizam o desmatamento da floresta amazônica. Caso os embargos se concretizem, estima-se que o Brasil perca cerca de US\$ 5 bilhões em investimentos estrangeiros (Reuters, 2020). Tais medidas têm impacto direto na renda do produtor rural e capacidade de investir em novas tecnologias sustentáveis.

Apesar dos impactos negativos aos setores econômicos, medidas de embargos como essas podem surtir em bons resultados a partir das mudanças das práticas produtivas e políticas ambientais. Um exemplo histórico é o caso da moratória da soja, quando boicotes a soja produzida em áreas de desmatamentos da Amazônia ocorrido na década de 2000 resultou em 2006 na criação do pacto "moratória da soja". A partir de pressões impostas pelo mercado internacional, governos, agroindústria e organismos de defesa ambiental firmaram um acordo no qual seriam adotadas medidas de prevenção ao desmatamento. A partir do pacto, entre os anos de 2006 e 2018, os oitenta e nove municípios que integravam o acordo conseguiram reduzir em 85\% a média anual de desmatamento (Cabral \& Gomes, 2013; Veiga, 2020).

A partir do cenário atual, percebe-se a urgente necessidade de adequação das práticas produtivas pelas empresas, o que inclui também, impor por parte do mercado nacional, pressões ao governo brasileiro por mudanças na política ambiental adotada nos últimos dois anos e que tem refletido de forma negativa na comercialização dos produtos em mercados internacionais. 
Sobre isso, Coral (2002) afirma que a contribuição para o desenvolvimento sustentável por parte das empresas, acontece quando há modificações nos sistemas produtivos, tornando-os mais eficientes e com impactos não negativos ao meio ambiente. Além disso, as empresas devem assumir o papel de recuperar as áreas degradadas e oferecer produtos e serviços que promovam a melhoria do desempenho ambiental dos consumidores.

Em propriedades rurais, a sustentabilidade é alcançada através da interação e combinação entre os sistemas agroindustriais, econômicos, sociais e ecossistemas naturais. Ademais, a sustentabilidade na agropecuária requer não somente a recuperação dos recursos naturais utilizados na operacionalização dos negócios, mas também, a necessidade de manutenção e/ou recomposição das áreas da propriedade e entorno, bem como das áreas de reserva legal e preservação permanente (Souza, 2012).

Em sistemas agroindustriais, o planejamento estratégico deve levar em conta a utilização das áreas produtivas contemplando uma visão sistêmica sobre a perspectiva de uso adequado e sustentável dos recursos naturais; uso e conservação dos recursos apoiados nos conhecimentos de ecologia agrícola; adoção de sistemas produtivos diversificados, integrados e adaptados aos ecossistemas e ao tratamento e destinação dos resíduos sólidos e estruturas de saneamento; levantamento das capacidades de utilização do solo, considerando suas propriedades físicas, químicas e biológicas, de modo a melhorar ou recuperar suas características; adoção de práticas sustentáveis de manejo e conservação das águas; as características socioeconômicas e culturais da comunidade - as características de cada comunidade devem sempre ser consideradas, não somente quanto aos limites geográficos, mas sobretudo, nos limites definidos pelas relações culturais, econômicas, sociais e políticas -; interesse dos atores sociais envolvidos na atividade; mercado-alvo; e fatores econômicos (Souza, 2012).

Vale ressaltar que os negócios rurais não se restringem apenas ao setor primário, como se compreendia no passado, mas engloba hoje, um amplo agrupamento de inter-relações e interdependências produtivas, mercadológicas e tecnológicas (Callado, 2011). Dessa forma, a compreensão dos sistemas agroindustriais requer o entendimento, por meio de uma visão sistêmica, sobre como o mercado encontra-se organizado e como sucede os fluxos monetários, produtivos e informacionais (Souza, 2019). Para Barros e Machado (2014) e Nychai (2005), as diferenciações nas cadeias produtivas se dão principalmente pelos fatores econômicos, sendo algumas commodities destinadas ao mercado estrangeiro e outras para consumo interno. Além disso, algumas commodities podem exigir maior grau de beneficiamento.

Com base na literatura utilizada, compreende-se que a adoção de práticas sustentáveis em unidades agropecuárias implica em ganhos para o produtor, como melhoria da imagem da empresa junto ao mercado consumidor e ao setor de atuação; proporciona maiores oportunidades de comercialização; beneficia a comunidade no entorno; traz melhoria na qualidade de vida da comunidade, bem como, aos consumidores a partir da produção de alimentos mais saudáveis; auxilia na conservação e recuperação do ambiente; além de ampliar a participação e expansão de mercado com a diversificação dos produtos (Santos, Walter \& Bertolini, 2019; Pletsch, Casali, Baggio \& Turcato, 2019). Como dificuldades enfrentadas na adoção de práticas sustentáveis, é possível citar os custos para o cumprimento das leis ambientais; produção sazonal; dificuldades para alinhar a oferta a demanda; custos de produção e gargalos logísticos (Lopes, Lowery \& Peroba, 2016; Renzcherchen, Siatkowski, Lenarte \& Stefano, 2020).

Assim, a partir da característica de cada negócio rural, se dará a busca pela sustentabilidade e planejamento das atividades operacionais. Conforme Buarque (1999) a sustentabilidade se alcança através das mudanças sociais e elevação das oportunidades da sociedade, compatibilizando com o crescimento e desenvolvimento econômicos, preservação ambiental, melhoria da qualidade de vida e equidade social, firmando um compromisso com o futuro e solidariedade com as próximas gerações. 


\section{Conclusão}

A agropecuária tem sido para o Brasil uma importante fonte de renda, equilíbrio da balança comercial e abastecimento do mercado nacional. No panorama mundial, o agronegócio brasileiro tem se destacado tanto pela sua diversificação quanto pela competitividade, obtida especialmente em virtude dos fatores naturais e tecnologias empregadas.

Em termos de sustentabilidade empresarial, o agronegócio tem ocupado uma posição estratégica quanto as dimensões econômica, social e ambiental, tornando-se referência mundial em pesquisa e desenvolvimento e tecnologias empregadas na agropecuária. No entanto, dada a complexidade da sua cadeia produtiva e a nova política ambiental adotada nos últimos dois anos pelo governo, a produção agropecuária brasileira tem sido constantemente associada a impactos ambientais e sociais negativos, o que tem resultado em sanções aos produtos nacionais. Assim, mesmo com a projeção de crescimento e expansão da produção nacional e os importantes resultados alcançados no ano de 2020, é imprescindível que os produtores agropecuaristas atuem em consonância com a conscientização do mercado consumidor frente a preservação ambiental e apesar da nova política ambiental de abrandar a legislação, busquem aliar a produção à sustentabilidade empresarial.

Após análise dos estudos realizados sobre o setor nos últimos 15 anos, conclui-se que houveram muitos avanços no uso de tecnologias e estabelecimento de políticas ambientais, sendo o Brasil, um dos países com a legislação ambiental mais rica de todo o globo. A adoção de práticas sustentáveis na cadeia produtiva trouxe benefícios tanto para os produtores, com a oportunidade de diversificação dos produtos, bem como do mercado consumidor e comunidade no entorno. Além disso, a legislação ambiental brasileira tem garantido a conservação das reservas naturais e redução dos impactos socioambientais.

Contudo, nos últimos dois anos, as discussões sobre a flexibilização das leis ambientais, assim como, as demissões e cortes nos orçamentos destinados aos órgãos fiscalizadores têm lançado um alerta mundial sobre os danos ambientais que podem sofrer a biodiversidade brasileira. Além disso, aumenta-se a cobrança aos produtores brasileiros pela adoção de práticas sustentáveis no processo produtivo e medidas de contenção aos impactos ambientais.

Ao considerar a relevância econômica, social e ambiental do tema, entende-se como necessário o desenvolvimento de ações governamentais e corporativas voltadas ao monitoramento das práticas produtivas agropecuárias e responsabilidade frente a conservação do ambiente natural brasileiro.

Como limitação da pesquisa, aponta-se a baixa quantidade de trabalhos científicos que abordem especificamente a sustentabilidade empresarial no agronegócio. Ao longo da pesquisa bibliográfica, foi possível notar uma crescente produção de trabalhos com enfoque na sustentabilidade aplicada à agropecuária, mas uma quantidade reduzida de estudos sobre sustentabilidade empresarial no agronegócio brasileiro. Dessa forma, para pesquisas futuras, recomenda-se a realização de estudos de campo que abordem a sustentabilidade empresarial em distintos segmentos da agropecuária, tendo em vista a sua ampla gama de setores. Pesquisas dessa natureza podem contribuir para o melhor entendimento quanto aos segmentos mais sustentáveis do agronegócio brasileiro, bem como, os setores mais críticos.

\section{Referências}

Albuquerque, M. C. C. (1977). Quatro séculos de história econômica brasileira. McGraw-Hill, 1977.

Almeida, F. (2002). O bom negócio da sustentabilidade. Nova Fronteira.

Amaral, G. F., \& Guimarães, D. D. (2020). Panoramas Setoriais 2030: Agropecuária. Banco Nacional do Desenvolvimento Econômico e Social https://web.bndes.gov.br/bib/jspui/bitstream/1408/14235/2/Panoramas\%20Setoriais\%202030\%20-\%20Agropecu\%C3\%A1ria_P.pdf.

Ashley, P. A. (coord.). (2005). Ética e responsabilidade social nos negócios. (2a ed.), Saraiva.

Barbarini, T. A., \& De Mario, C. G. (2019). Alimentação saudável, saúde e sustentabilidade: Um debate sobre justiça social. Mediações, 25(1), 188-206. $10.5433 / 2176-6665.2020 .1 \mathrm{v} 25 \mathrm{n} 1 \mathrm{p} 188$.

Barbieri, J. C., \& Cajazeira, J. E. R. (2012). Responsabilidade social empresarial e empresa sustentável: Da teoria à prática. (2a ed.), Saraiva. 
Bardin, L. (2016). Análise de conteúdo. Edições 70.

Barros, J. R. M., \& Machado, R. (2014). O Agronegócio Brasileiro. In Belluzo, L. G. M., Frischtak, C. R., \& Laplane, M. (Orgs.). Produção de Commodities e Desenvolvimento Econômico (pp. 43-53). Campinas: UNICAMP.

Barros, R. A., Andrade, E. O., Vasconcelos, A. C. F., \& Cândido, G. A. (2010). Práticas de Sustentabilidade Empresarial no APL calçadista de Campina Grande-PB: Um estudo de caso. Revista Gestão Industrial, 6(1), 157-177. 10.3895/S1808-04482010000100008.

Buarque, S. C. (1999). Metodologia de planejamento do desenvolvimento local e municipal sustentável. (2a ed.), IICA.

Bruno, R. (2019). A humilhação como recurso de poder: Empregadores e trabalhadores rurais escravizados no Brasil contemporâneo. In Bruno, R., \& Leite, S. P. (Orgs.). O rural brasileiro na perspectiva do século XXI. (pp. 151-165). Garamond.

Cabral, E. R., Gomes, S. C. (2013). Gestão Ambiental Pública em municípios com forte correlação entre desmatamento e expansão da pecuária, da soja e da madeira. Ensaios FEE, Porto Alegre, 34(1), 167-194. https://revistas.dee.spgg.rs.gov.br.

Callado, A. A. C. (Org.). (2011). Agronegócio. (3a ed.), Atlas/PADR.

Calmon, P. (1937). História social do Brasil: Espírito da sociedade colonial. (2a ed.), Companhia Editora Nacional.

Calmon, P. (2002). História da civilização brasileira. Senado Federal. (Coleção Biblioteca Básica Brasileira).

Carmo, L. O. (2015). Evolução da Responsabilidade Social Empresarial e a introdução ao caso brasileiro. Revista de Administração Geral, 1(2), 118-137. Recuperado em 17 abr. 2021 de http://periodicos.unifap.br/index.php/administracao.

Carroll, A. B., \& Shabana, K. M. (2010). The business case for corporate social responsibility: A review of concepts, research and practice. International Journal of Management Reviews, 12(1), 85-105. 10.1111/j.1468-2370.2009.00275.x.

Cavalcanti Filho, F. A., \& Cartaxo, G. A. A. (2015, 13 a 16 outubro). Práticas de produção sustentável aplicadas no agronegócio. XXXV Encontro Nacional de Engenharia de Produção, Fortaleza, CE, Brasil. http://www.abepro.org.br/biblioteca/TN_STO_216_277_26665.pdf

Centro de Estudos Avançados em Economia Aplicada. (2020). In PIB do Agronegócio cresce 3,81\% em 2019. Centro de Estudos Avançados em Economia Aplicada. https://www.cepea.esalq.usp.br/upload/kceditor/files/Cepea_PIB_CNA_2019(1).pdf.

Claro, P. B. O., Claro, D. P., \& Amâncio, R. (2008). Entendendo o conceito de sustentabilidade nas organizações. Revista de Administração, São Paulo, 43(4), 289-300. https://doi.org/10.1590/S0080-21072008000400001.

Coral, E. (2002). Modelo de Planejamento Estratégico para a Sustentabilidade Empresarial. [Tese de Doutorado, Universidade Federal de Santa Catarina] Repositório Universidade Federal de Santa Catarina. https://repositorio.ufsc.br/bitstream/handle/123456789/82705/189235.pdf?sequence=1\&isAllowed=y.

Costa, P. S. P., \& Lino, E. N. S. (2018). O agronegócio no Brasil: Uma análise contra hegemônica voltada à sustentabilidade e ao direito ao desenvolvimento. Revista Videre, 10(20), 14-28. 10.30612/videre.v10i20.7224

Donaire, D. (1999). Gestão ambiental na empresa. (2a ed.), Atlas.

Elkington, J. (1997). Cannibals with forks: The triple bottom line of 21st century business. Capstone Publishing Limited.

Organização das Nações Unidas para a Alimentação e a Agricultura (1999). La Agricultura Urbana y Periurbana. Comite de Agricultura. Roma: FAO.

Gazzoni, D. L. (2013). A sustentabilidade da soja no contexto do agronegócio brasileiro e mundial. Londrina: Embrapa Soja. https://www.infoteca.cnptia.embrapa.br/bitstream/doc/973921/1/Doc344online.pdf.

Gomes, C. S. (2019). Impactos da expansão do agronegócio brasileiro na conservação dos recursos naturais. Cadernos do Leste, (19)19, 63-78. Recuperado em 17 abr. 2021 de https://periodicos.ufmg.br/index.php/caderleste/article/view/13160/10396.

Governo do Brasil. (2021, $19 \quad$ abril). Painel Estatístico $\quad$ de $\quad$ Pessoal: http://painel.pep.planejamento.gov.br/QvAJAXZfc/opendoc.htm?document=painelpep.qvw\&lang=en-US\&host=Local\&anonymous=true.

Greenpeace Brasil. (2020). Brasil em Chamas: do Pantanal à Amazônia, a destruição não conhece fronteiras. Greenpeace Brasil. https://www.greenpeace.org/brasil/blog/brasil-em-chamas-negando-as-aparencias-e-disfarcando-as-evidencias/.

Guimarães, V. M. B., \& Pirineus, P. C. S. (2020). Resistências jurídico-políticas ao desenvolvimento agroecológico no Brasil. Revista de Direito Econômico e Socioambiental, 11(2), 288-320. 10.7213/rev.dir.econ.soc.v11i2.27161

Instituto Brasileiro de Geografia e Estatística. (2017). Censo Agropecuário 2017. Instituto Brasileiro de Geografia e Estatística. https://sidra.ibge.gov.br/pesquisa/censo-agropecuario/censo-agropecuario-2017.

Instituto Brasileiro de Geografia e Estatística. (2020). PIB cai 1,5\% no primeiro trimestre de 2020. Instituto Brasileiro de Geografia e Estatística. https://agenciadenoticias.ibge.gov.br/agencia-sala-de-imprensa/2013-agencia-de-noticias/releases/27837-pib-cai-1-5-no-1-trimestre-de-2020. 29/05/2020.

Instituto de Pesquisa Econômica Aplicada. (2020). Carta de Conjuntura 2021. Instituto de Pesquisa Econômica Aplicada, (49). https://www.ipea.gov.br/portal/images/stories/PDFs/conjuntura/201124_cc_49_nota_21_agropecuaria.pdf.

Jornal do Brasil (2020, 01 outubro). Reputação de produtos brasileiros sofre com boicotes europeus e política de Bolsonaro, diz analista. Jornal do Brasil. https://www.jb.com.br/economia/2020/06/1024240-reputacao-de-produtos-brasileiros-sofre-com-boicotes-europeus-e-politica-de-bolsonaro--diz-analista.html. 
Kirschner, P., Vione, C. I. B., Fernandes, S. B. V., \& Thesing, N. J. (2020). Sustentabilidade no Ambiente do Agronegócio. Educação Ambiental em Ação, 19(74), 1-10. http://revistaea.org/artigo.php?idartigo $=3385$

Lima Filho, D. O., Azevedo, D. B., Teixeira, M.G., \& Silva, E. B. (2017). A dimensão ambiental da sustentabilidade em pauta no setor de bovinocultura de corte: Análise dos diálogos entre stakeholders sul-mato-grossenses. Revista Metropolitana de Sustentabilidade, 7(2), 43-67. https://revistaseletronicas.fmu.br/index.php/rms/article/view/1048/pdf

Lopes, D., Lowery, S., \& Peroba, T. L. C. (2016). Crédito rural no Brasil: Desafios e oportunidades para a promoção da agropecuária sustentável. Revista BNDS, (45), $\quad$ 155-196. $\quad$ https://web.bndes.gov.br/bib/jspui/bitstream/1408/9518/1/5$\% 20 \mathrm{Cr} \% \mathrm{C} 3 \%$ A 9 dito\%20rural\%20no\%20Brasil\%20desafios\%20e\%20oportunidades\%20para\%20a\%20promo\%C3\%A7\%C3\%A3o\%20da\%20agropecu\%C3 $\%$ A1ria\%20sustent\%C3\%A1vel.pdf

Maia, M. F. R. (2015). Ética e Responsabilidade Social Empresarial - A contribuição das empresas na promoção da equidade e da justiça social: Análise a partir da experiência de algumas empresas do setor têxtil do Norte de Minas - MG - Brasil. [Tese de Doutorado, Universidade Nova de Lisboa] Repositório Universidade Nova de Lisboa. https://run.unl.pt/bitstream/10362/16235/1/TESE\%20FINAL.pdf

Melo, M. P., Brandão, A. D., \& Lima, J. D. (2018). Relação entre sociedade e natureza e desdobramentos do agronegócio na contemporaneidade. Revista Geografia Acadêmica, 12(1), 36-49. https://revista.ufrr.br/rga/article/view/4861/2506

Menezes, T. C. C. (2019). Gestão Territorial e desenvolvimento: Análise comparativa de políticas territoriais na Amazônia. In Bruno, R., \& Leite, S. P. (Orgs.). O rural brasileiro na perspectiva do século XXI. (pp. 249-267). Garamond.

Ministério da Agricultura, Pecuária e Abastecimento. (2020). Projeções do Agronegócio: Brasil 2019/20 a 2029/30. Projeções de longo prazo. Brasília: Ministério da Agricultura, Pecuária e Abastecimento.

Nychai, L. (2005). Caracterização do Modelo de Agroindustrialização de pequeno porte voltado à propriedade rural familiar no município de GuarapauavaPR. [Dissertação de Mestrado, Universidade Estadual do Oeste do Paraná] Repositório Unioeste. http://tede.unioeste.br/bitstream/tede/2890/1/Luci\%20Nychai.pdf.

Oliveira, R. C. A. (2012). A Responsabilidade socioambiental e a sustentabilidade corporativa: estudo de caso da Celtins. [Dissertação de Mestrado, Universidade Federal do Tocantins] Biblioteca da Universidade Federal do Tocantins. https://repositorio.uft.edu.br/bitstream/11612/86/1/Rita\%20Oliveira\%20-\%20Disserta\%c3\%a7\%c3\%a3o.pdf.

Parmar, B. L., Freeman, R. E., Harrison, J. S., Wicks, A. C., Colle, S., \& Purnell, L. (2010). Stakeholder theory: The state of the art. Academyof Management Annals, 4(4), 403-445. 10.1080/19416520.2010.495581.

Plestch, L. M. M., Casali, M. S., Baggio, D. K., \& Turcato, J. C. (2019). Desenvolvimento sustentável na suinocultura e bovinocultura: A experiência das propriedades do município de Três Passos-RS. IGEPEC, 23(1), 51-73, 2019. https://doi.org/10.48075/igepec.v23i1.18759

Reijntnes, C., Haverkort, B., \& Waters-Bayer, A. (1992). Farming for the future: An introduction to low-externalinput and sustainable agriculture. London: The Macmillan Press.

Reis, C. N., \& Medeiros, L. E. (2009). Responsabilidade Social das empresas e o balanço social. Atlas.

Reuters. (2020, 19 junho). Investidores europeus ameaçam desinvestir no Brasil devido a desmatamento. G1.globo. https://g1.globo.com/economia/noticia/2020/06/19/investidores-europeus-ameacam-desinvestir-no-brasil-devido-a-desmatamento.ghtml.

Romano, J. O., \& Vega, G. C. (2019). Desafios para o BRICS: Multipolaridade, nova arquitetura econômica internacional e sustentabilidade ambiental. In Bruno, R., \& Leite, S. P. (Orgs.). O rural brasileiro na perspectiva do século XXI. (pp. 205-223). Rio de Janeiro: Garamond.

Rossi, R. A., \& Santos, E. (2018). Conflito e regulação das águas no Brasil: A experiência do Salitre. Caderno CRH, 31(82), 151-167. http://dx.doi.org/10.1590/S0103-49792018000100010

Santos, M., \& Glass, V. (2018). Atlas do agronegócio: Fatos e números sobre as corporaçães que controlam o que comemos. Fundação Heinrich Boll; Fundação Rosa Luxemburgo.

Santos, T. C. B., Walter, S. A., \& Bertolini, G. R. F. (2019). Práticas de sustentabilidade como estratégia de legitimidade organizacional em uma cooperativa agropecuária. Revista Metropolitana de Sustentabilidade, 9(3), 36-63, 2019. revistaseletronicas.fmu.br/index.php/rms

Schneider, S. (2010). Situando o desenvolvimento rural no Brasil: O contexto e as questões em debate. Revista de Economia Política, 30(3), 511-531. https://doi.org/10.1590/S0101-31572010000300009.

Smalci, A., Silva, O. R., Fernandes, C. A., \& Quel, L. F. (2020). Fatores determinantes e condicionantes para inovação e competitividade no setor do agronegócio brasileiro. Revista Metropolitana de Sustentabilidade, 10(1), 6-21. revistaseletronicas.fmu.br/index.php/rms

Renzcherchen, S. K., Siatkowski, A., Lenarte, D. \& Stefano, S. R. (2020, outubro). Desenvolvimento de modelos de gestão e empreendedorismo sustentável no agronegócio de pequeno e médio portes. Congresso Internacional de Administração, Ponta Grossa, PR, Brasil, 7.

Shalders, A. (2021, 5 fevereiro). Com Bolsonaro, área ambiental do governo já perdeu 10\% dos funcionários. BBC.com. https://www.bbc.com/portuguese/brasil-55849937

Silva, A. A., Galon, L., Ferreira. F. A., Tiron, S. P., Ferreira, E. A., Silva, A. F., Aspiazú, I., \& Agnes, E. L. (2009). Sistema de plantio direto na palhada e seu impacto na agricultura brasileira. Revista Ceres, 56(4), 496-506. http://www.ceres.ufv.br/ojs/index.php/ceres/article/view/3458.

Soglio, F. K. D. (2016). A Agricultura Moderna e o Mito da Produtividade. In Soglio, F. K. D., \& Kubo, R. R. (Orgs.). Desenvolvimento, agricultura e sustentabilidade (11-38). Editora da UFRGS. 
Research, Society and Development, v. 10, n. 7, e30210716567, 2021

(CC BY 4.0) | ISSN 2525-3409 | DOI: http://dx.doi.org/10.33448/rsd-v10i7.16567

Souza, E. R. (2012). Gestão Ambiental de propriedades rurais. EMATER-MG.

Souza, L. J. (2019). Indicadores de desempenho para a agroindústria: Proposta às indústrias beneficiadoras de arroz de Rondônia. [Dissertação de Mestrado, Universidade Federal do Paraná] Biblioteca de Ciências Sociais Aplicadas. https://acervodigital.ufpr.br/bitstream/handle/1884/59656/R\%20-\%20D\%20\%20LUCAS\%20JOSE\%20DE\%20SOUZA.pdf?sequence=1\&isAllowed=y

Spers, V. R. E., Mota, M. G. M., \& Martineli, P. P. H. (2014). Conversando sobre Administração: Foco na Responsabilidade Social. Life.

Strobel, J. S. (2005). Modelo para mensuração da sustentabilidade corporativa através de indicadores. [Dissertação de Mestrado, Universidade Federal de Santa Catarina] $\quad$ Repositório $\quad$ Universidade $\quad$ Federal $\quad$ de Santa https://repositorio.ufsc.br/bitstream/handle/123456789/102809/223696.pdf?sequence=1\&isAllowed=y.

Székely, F., \& Knirsch, M. (2005). Responsible Leadership and Corporate Social Responsibility: Metrics for sustainable Performance. European Management Journal, 23(6), 628-647. https://doi.org/10.1590/S0101-31572010000300009.

Tarapanoff, K. M. A. (2018). Monitoramento do agronegócio brasileiro sustentável em relação ao mercado global. Ciência da Informação, 45(3), 15-30. http://revista.ibict.br/ciinf/article/view/4044

Triviños, A. N. S. (2008). Introdução à Pesquisa em Ciências Sociais: A pesquisa qualitativa em educação. Atlas

Veiga, E. (2020, 20 junho). Europa aperta cerco contra produtos brasileiros. Deutsche Welle. https://www.dw.com/pt-br/europa-aperta-o-cerco-contraprodutos-brasileiros/a-53872241.

Vellani, C. L., \& Ribeiro, M. D. S. (2009). Sustentabilidade e contabilidade. Revista Contemporânea de Contabilidade, 6(11), 187-206. ISSN $1807-1821$.

Vergara, S. C. (2007). Projetos e relatórios de pesquisa em administração. (9a ed.), Atlas. 